J. Asiat. Soc. Bangladesh, Sci. 39(2): 259-267, December 2013

\title{
BREEDING BIOLOGY OF GUPPY FISH, POECILIA RETICULATA (PETERS, 1859) IN THE LABORATORY
}

\author{
REZA MD. SHAHJAHAN ${ }^{1}$, MD. JUBAYER AHMED, ROWSHAN ARA BEGUM \\ AND MD. ABDUR RASHID \\ Department of Zoology, University of Dhaka, Dhaka, Bangladesh
}

\begin{abstract}
The breeding biology of guppy fish, Poecilia reticulata (Cyprinodontiformes: Poiciliidae) was studied during March 2008 to May 2009 in 'Zoological garden laboratory', Curzon Hall campus, Dhaka University. Guppy bred all over the year except in the winter months December and January with a peak period in July. They were viviparous and multiple breeders, i.e., give birth to fry several times in the breeding season. The mean egg diameter was measured to be $(1.02 \pm 0.08 \mathrm{~mm})$ and fecundity was estimated (40-89) per gram of body weight. The gestation period ranged 25-35 days with an average of $28.1 \pm 2.12$ days. Developmental stages observed under a compound microscope were classified based on the changes in the developing eye, such as optic cup, early-eyed, middle-eyed, late-eyed, very late-eyed etc. It was noticed that tail portion comes out first at birth. The number of fry per brood ranged from 12 to 60 . New born fries were observed with transparent or blackish in colour having slender body with jaws developed on mouth and were fully capable of swimming, eating, and avoiding danger. Guppy grew rapidly, attained sexual maturity at $8-10$ weeks and reached full size in 6 months.
\end{abstract}

Key words: Guppy fish, Poecilia reticulata, Breeding biolog

\section{Introduction}

Popular aquarium fish, Poecilia reticulata commonly known as 'guppy' was introduced in various countries for mosquito control and often loosely called 'mosquito fish'. It has been found to establish itself in both fresh and polluted waters (Ahmed et al. 1985). It introduced in India as early as 1910 to control mosquito (Kaira et al. 1967). This larvivorous fish are quite tolerant of a variety of water conditions thus can be used as predators of mosquito larvae and they can be moved to water areas where they are needed (Travis 1957).

Synthetic insecticides are widely used for mosquito control throughout the world, and some of these has long residual activities and affect the environment adversely. Many mosquito species has developed resistance to a variety of insecticides (WHO 1986). The development of resistance in mosquitoes to insecticides, environmental pollution, the high cost of control due to short duration of action of insecticides and toxicity of newer

${ }^{1}$ Corresponding author: Email: reza.shahjahan56@gmail.com 
insecticides and other reasons have given rise to a new thinking to find out other ways of mosquito control. Among the various vector control measures, the biological control method is favored due to its cost effectiveness. Larvivorous fish have been used in mosquito control on and off for many years in different parts of the world (Ahmed et al. 1985). Guppies have the capacity to survive and multiply in both fresh and polluted waters to solve this problem. An understanding of the breeding biology of $P$. reticulata is a basic requirement for the successful proliferation of the fish, hence successful mosquito control. The guppy is suitable for mosquito control due to its flattened head, protruded mouth, small size and its voracious appetite for living on prey, especially insect larvae (Bay 1967). It is a viviparous fish and is capable of increasing its population in shallow or polluted water (Menon and Rajagopalan 1977). In Bangladesh no published information on the breeding of $P$. reticulata is available. Researches have been carried out on the bio-control of mosquito larvae by guppies (Ahmed et al. 1985, Khanum et al. 2002). Therefore, the present investigation was carried out on the breeding biology of $P$. reticulata in a controlled aquarium condition.

\section{Materials and Methods}

The experiments were conducted in Curzon Hall area of Dhaka University campus. A total of 40 fishes was collected from Kataban fish market and from different drains of Curzon Hall area and was transferred to rearing aquaria. Males were clearly distinguished by having modified anal fin taking the form of a gonopodium and in females, body colour was less bright and had swollen abdomen. Each of the aquaria contained 8-10 liters of water. Water was changed manually every two alternate days in the afternoon when the temperature of the aquarium water was close to that of the tap water. The guppy prefers hard water and can withstand salinity up to one ppt. So, half a tablespoon $(8 \mathrm{~g})$ of salt was mixed with 20 liter of water every time during water change. The broods were provided with bloodworms, Chironomus sp., mosquito larvae and commercial pallet feed as their food and given twice a day in the morning and at afternoon.

Diameter of eggs was measured for the estimation of the fecundity. Twelve ripe females of $P$. reticulata were randomly sampled and the fecundity was computed by counting the number of ova and the developing embryonic stages by dissecting the abdomen of the gravid female specimens. The developmental stages of the embryos inside the gravid females were observed by dissecting the gravid female's abdomen. Different embryonic stages found in the same mother fish at a time were observed with naked eye and under a compound microscope (10X). The newly born baby fish (fry) were observed in ten occasions, viz. (1hour, 1, 7, 14, 21, 28, 35, 42, 49 and 56 days) of age, till up to 8 weeks. 


\section{Results and Discussion}

The month wise reproduction of $P$. reticulata was observed throughout the year except in December and January (Fig. 1). Guppy began fry birth in February and ended in November with a peak in July. In February, comparatively few mother guppies gave birth. Hidebrand (1921) reported that the breeding season of guppy in the Southeastern U. S. begins in May and ends in September and October. Davis (1978) reported that in South-central Texas, the breeding season of Gambusia affinis, a closely related fish of guppy ranges from March to October with a peak in April.

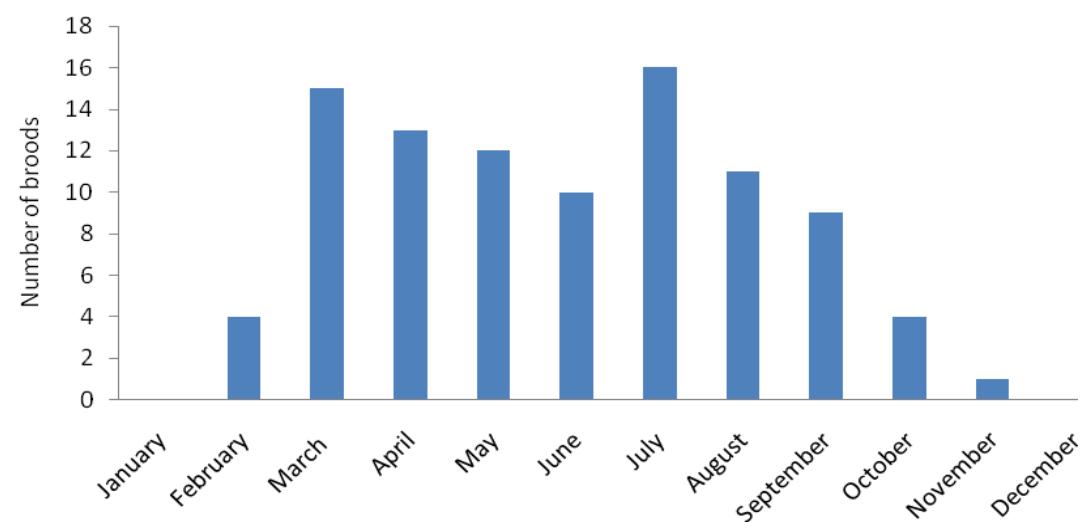

Fig. 1. Number of broods of Poecilia reticulata in different months of the year 2008-2009.

In the present study, it was observed that the gestation period of guppy was 25-35 days with an average of 28 days (Table 1). Guppy was reported to bring out broods at approximately four-week intervals (Ahmed et al. 1985). Krumholz (1948) reported that the average gestation period of $G$. affinis, a closely related fish of guppy ( $P$. reticulata), was 23-24 days. In guppy, fertilization is internal and takes place through mating of couples showing specific mating behavior. Male transfers sperms into female body by a modified anal fin called gonopodium. Male perform an S-shaped posture known as 'sigmoid display' and orientates himself in front of the females at the beginning of courtship. Collier (1936) and Paden (1975), obsereved courtship behaviour in mosquito fish, that was similar to the present study. Houde and Endler (1995) observed that females exhibit sexual preferences for males with larger color spots, which is displayed during elaborate "sigmoid" courtship displays.

The egg weight of 12 gravid females was $0.60 \pm 0.04 \mathrm{~g}$ (range, 0.54-0.68 g) and mean egg diameter was: $1.02 \pm 0.08 \mathrm{~mm}$ (range, 0.9-1.2mm) (Table 1). Fecundity was expressed as the total number of eggs produced by fully mature gravid female of $P$. 
reticulata during the peak period of their breeding. The fecundity of guppy under different body sizes as well as per gm estimated body weight has been shown in Table 1 . It was observed that total fecundity of various body sizes (range, $0.54-0.68 \mathrm{~g}$ ) was 2252 , while estimated mean fecundity per gm body weight was estimated $63 \pm 13.45$ (range, 40-89). The results indicate that the fecundity was directly proportional to the body weight of the fish, i.e., the fecundity increased with the increase in body weight. It was found that the number of the fry per brood ranged from 12-60 and the number also varied with the size of female. Larger females produce large number of offspring than smaller fish. Shikano and Fujio (1997) reported that the female guppy gave birth 2 to100 fry, but the typical range is between 5 and 30 . Nutritional balance, water condition or differences in rearing procedure might be the cause of the variation.

Table 1. Fecundity, size of ova and gestation period of the gravid females of Poecilia reticulata $(\mathrm{n}=12)$.

\begin{tabular}{|c|c|c|c|c|c|}
\hline $\begin{array}{l}\text { Body length } \\
(\mathrm{cm}) \\
(\text { mean } \pm \mathrm{SD})\end{array}$ & $\begin{array}{l}\text { Body weight } \\
(\mathrm{g}) \\
(\text { mean } \pm \text { SD) }\end{array}$ & $\begin{array}{l}\text { Total fecundity } \\
(\text { mean } \pm \text { SD) }\end{array}$ & $\begin{array}{l}\text { Estimated } \\
\text { fecundity/g } \\
\text { body weight } \\
(\text { mean } \pm \text { SD) }\end{array}$ & \begin{tabular}{|l} 
Egg \\
diameter \\
$(\mathrm{mm})$ \\
$($ mean \\
$\pm \mathrm{SD})$
\end{tabular} & 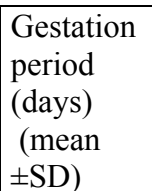 \\
\hline$(3.98 \pm .208)$ & $(0.60 \pm .04)$ & $(39.58 \pm 7.76)$ & $(63 \pm 13.45)$ & $(1.02 \pm .08)$ & $(28.1 \pm 2.12$ \\
\hline
\end{tabular}

Embryonic development (in womb): As guppy can store the sperm of their mates, eggs may become fertilized at different times facilitating the availability of several successive embryonic stages at a time in a single mother fish. Studies on embryogenesis have been limited by the fact that fertilization is internal and guppies are live-bearers. Normal development of guppy embryos was observed at various times after dissecting gravid mother guppies. Development of each batch of eggs was found to be slightly asynchronous, most likely due to asynchronous fertilization. Embryos were withdrawn from the gravid guppy and were observed. Eleven stages (Plate 1a-k) could be observed during the study.

Fertilized eggs: Fully swollen fertilized eggs were observed as brownish yellow in colour, rounded in shape and translucent (Plate 1a). The mature ovum contains oil droplets that are evenly distributed over the yolk surface similar to the observation stated by Martyn et al. (2006).

Blastodisc: After fertilization, the oil droplets coalesce underneath the embryo proper, which forms a blastodisc (Plate 1b).

Gastrula: Gastrula was viewed under microscope with clearly visible archenteron (Plate 1c).

Optic cup stage: At the optic cup stage (Plate 1d), the eyes remain unpigmented, blood vessels of the portal system are visible in the lower part of the yolk sac. 
Early-eyed stage: During the early-eyed period, pigmentation of the eye, including the choroid, gradually increases, the pectoral fin buds emerge, and somitic as well as nonsomitic muscles differentiate (Plate 1e).

Middle-eyed stage: During the middle-eyed stage, melanophores first appear above the midbrain and subsequently behind the midbrain-hindbrain boundary.

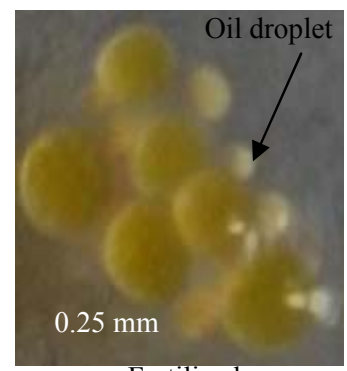

a. Fertilized eggs

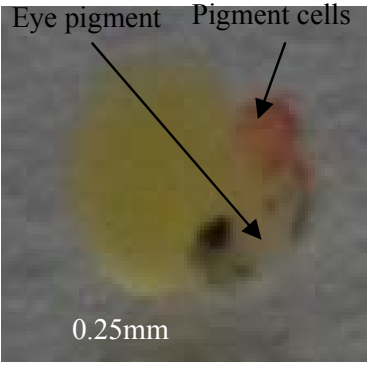

e. Early-eyed stage

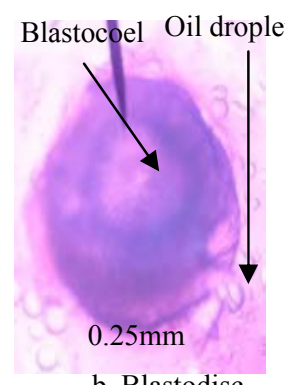

b. Blastodisc

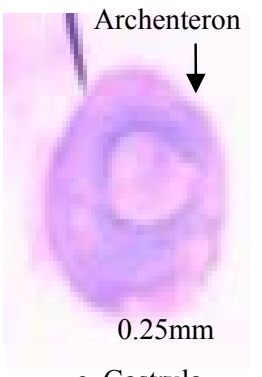

c. Gastrula

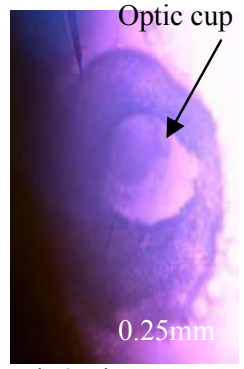

d. Optic cup stage

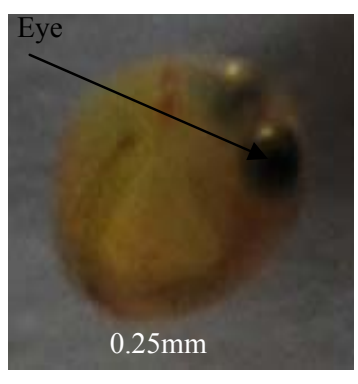

f. Middle-eyed stage

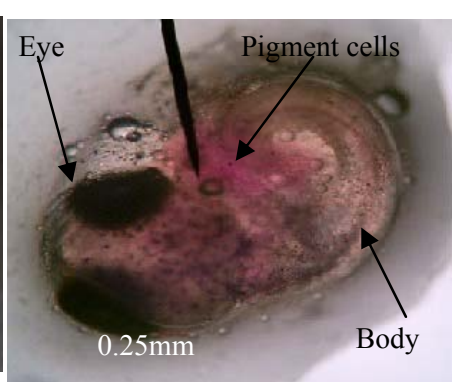

g. Late-eyed stage

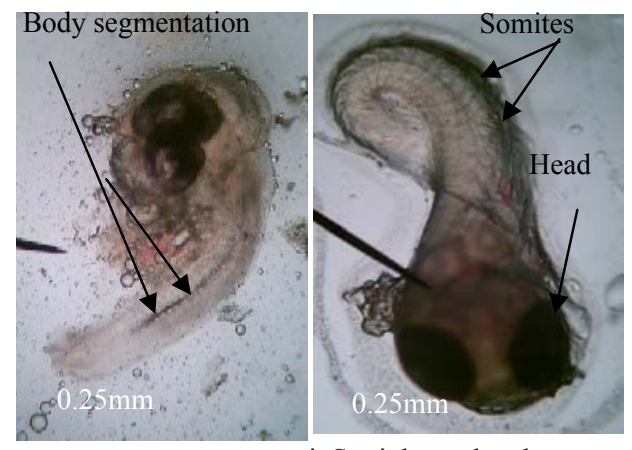

h. Very late-eyed stage i. Straightened embryo

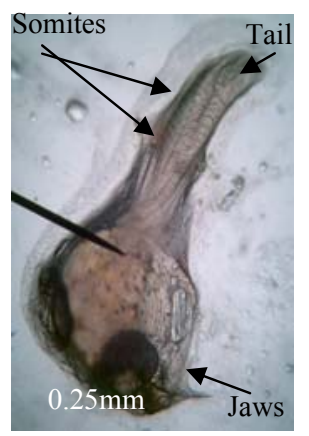

j. Matured embryo

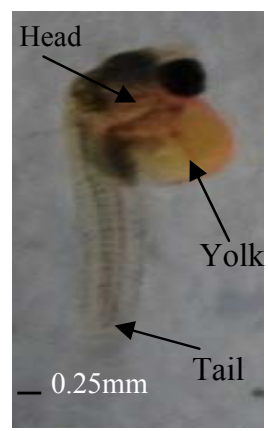

k. Embryo ready to come $n+$

Plate. 1. Successive stages of embryo found in gravid guppy, Poecilia reticulata. The stages $\mathrm{b}, \mathrm{c}, \mathrm{d}, \mathrm{g}, \mathrm{h}, \mathrm{i}$ and $\mathrm{j}$ were observed by compound microscope (10X) whereas a,e,f and $\mathrm{k}$ were taken directly by 13 megapixels camera. Name of the stages were according to Martyn et al. 2006. 
Late-eyed stage: In the subsequent late-eyed stage, a line of dark pigment cells appears that demarcates the horizontal midline, and the mostly stellate black pigment cells on the head increase in number, size and density, and become more dendritic in their appearance. Head bent with chromatophores on it, eyes were large and huge blood vessels appeared in yolk sac. Different regions of the embryo are often covered by melanophores of different shapes (Goodrich et al. 1944 and Tavolga 1949).

Very late-eyed stage: During very late-eyed stage (Plate 1h), clear segmentation of the embryo was visible. The almost rectangular flexure between the head and the trunk was gradually straightened.

Straightened embryo: The myotome consists of approximately 22 somites (Plate 1i).

Matured embryo: Embryo was then observed with developing jaws and became mature (Plate $1 \mathrm{j}$ ). Matured embryo was ready to come out (Plate $1 \mathrm{k}$ ). Some of the mature embryo absorbed its yolk completely and retracted the yolk sac, but the rest came out with a small amount of yolk. The developmental stages in present observation were similar to those of Goodrich et al. (1944) Tavolga (1949) and Martyn et al. (2006).

The neonate fry was knocked by the mother with her head to learn swimming and they floated and moved around the aquarium. The fries took birth with jaws developed on mouth. So, they could easily take food immediately after birth. It was observed that from the moment of birth, each fry was fully capable of swimming, eating and avoiding danger. Shikano and Fujio (1997) also made similar observation.

It was observed that females typically mate with more than one male. Evans and Magurran (2000) noted the similar facts in guppies during their sexually receptive phase. Females have the ability to store sperm, so that they can give birth many times, after mating with a male only once. Three to five times hatching was observed after a single mating in several couples during this study. Constantz (1989) also observed that female guppies store sperm for several months. It was observed that $P$. reticulata hatch its first brood at the age of 3-4 months. Menon and Rajagopalan (1977) also reported that this fish can reproduce at the age of 90 days. After giving birth, the female became ready for conception again within only a few hours.

Development after birth: Newly hatched fries were blackish or transparent and slender with chromatophore on head measuring from 6.5 to $7.5 \mathrm{~mm}$ in length. They settled down at the bottom of the aquarium and searched food in the stones within 1-2 hours. Characteristics of the different stages of fry development are briefly pointed belowFry, just after birth: Transparent, some are blackish or grayish in colour. Body slender, about 6.5 7.5 mm long. Pectoral fins were larger than caudal.

One hour after hatching: All of the fry appeared transparent within few hours of birth. Approximate body size was $6.5 \sim 8.0 \mathrm{~mm}$. 
One day old fry: Fins clearly observed, pelvic fin is smaller than pectoral. Caudal fin with dark spot. Length of the body was $6.8 \sim 8.5 \mathrm{~mm}$.

7-day old fry: Caudal fin somewhat flat clearly appeared as a tail. A longitudinal thread like structure, the alimentary canal was observed in the transparent body. Body length was $7.0 \sim 9.0 \mathrm{~mm}$.

14-day old fry: A primary concept might be achieved of sex differences. Female abdomen was somewhat wider than male. Body measured 7.5 9.5 mm in length. Anal fins of both sexes were similar.
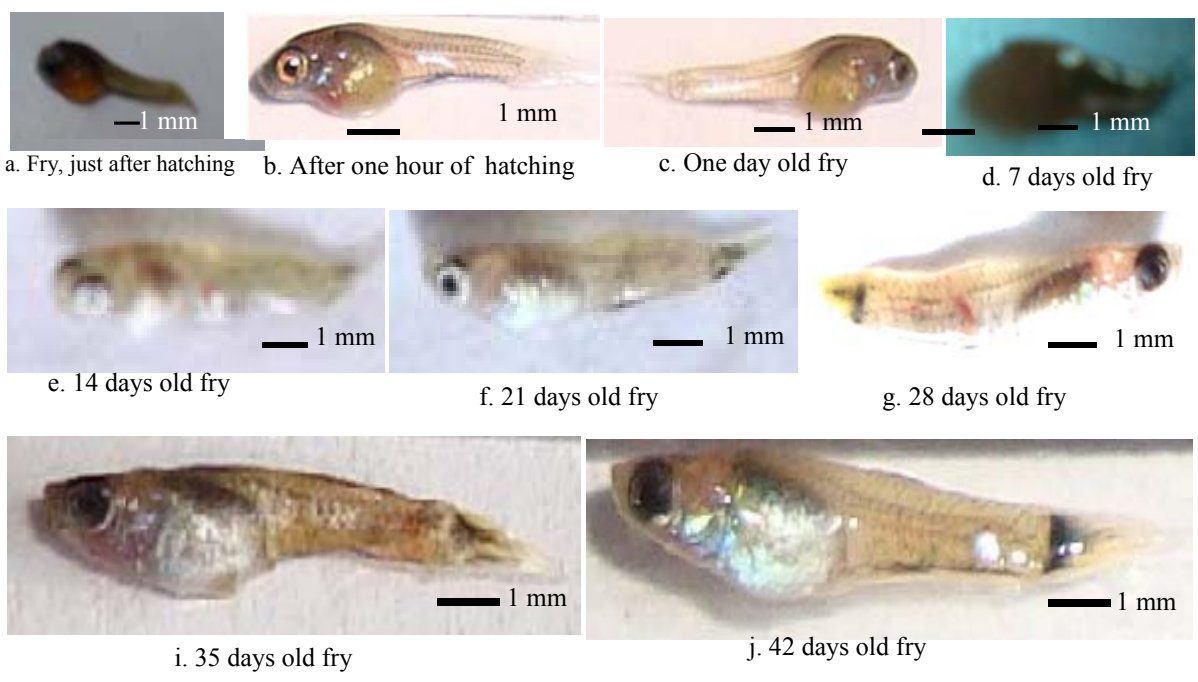

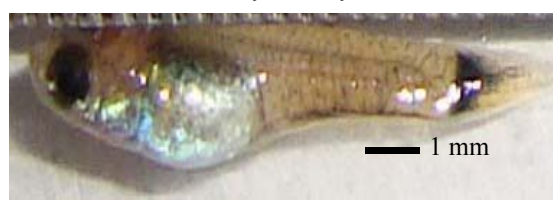

k. 49 days old fry

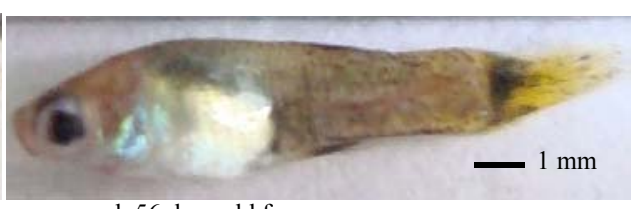

1. 56 days old fry

Plate 2. Successive stages of fry development of Poecilia reticulate.

21-day old fry: The anal fin of male becomes elongated and tube shaped while in the female it becomes small and rounded. Fin rays observed in male but not in female.

28-day old fry: Caudal fin of the male becomes coloured, especially appeared as brownish. Female caudal fin was blackish in colour. Size of female became larger compared to that of the male. The range of the body length was $8 \sim 9.5 \mathrm{~mm}$. 
35-day old fry: Male and female were clearly distinguished according to their size, tail and anal fin. The abdomen of female became larger and flatter compared to that of the male. Body size ranged $8.5 \sim 10 \mathrm{~mm}$ on average.

42-day old fry: Blacked tail clearly appeared in female. Body length was 91 0.5 mm.

49-day old fry: Male initiate their sexual traits and moved behind female. In some cases, a dark spot surrounding the anus and urinogenital area known as 'gravid spot' present in females while that was absent in males. Approximate body length was $9.5 \sim 12 \mathrm{~mm}$.

56-day old fry: The male and female become sexually mature. Fins were fully developed. Approximate body length was $11.5 \sim 14 \mathrm{~mm}$. Body and fins were brightly coloured in male.

The full size of male ranged $3 \sim 5 \mathrm{~cm}$ and female ranged $4 \sim 7 \mathrm{~cm}$ and reached full size at about 6 months.

\section{References}

Ahmed, T.U., M.K.R. Rabbani and Meher-e-Khuda. 1985. Observation of the larvivorous efficiency of Poecilia reticulata (Cyprinodontiformes: cyprinodontidae). Bangladesh $J$. Zool. 13: 7-12.

Bay, E.C. 1967. Mosquito control by fish. Chronicle, WHO. 21: 415.

Collier, A. 1936. The mechanism of internal fertilization in Gambusia. Copeia. 45-53pp.

Constantz G.D. 1989. Reproductive biology of Poeciliid fishes. In: Meffe GK, Snelson F. F, editors. Ecology and evolution of Livebearing fishes (Poeciliidae). New Jersey: Prentice Hall. p 33-50.

Davis, J.R. 1978. Reproductive season in Gambusia affinis and Gambusia geiseri (Osteichthyes: Poeciliidae) from Southcentral Texas. Texas J. Sci. 30: 97-99.

Evans, J.P. and A. E. Magurran. 2000. Multiple benefits of multiple mating in guppies. PNAS. 97(18):10074-10076

Goodrich, H.B., N.D. Josephson, J.P. Trinkhaus and J.M. Slate. 1944. The cellular expression and genetics of two new genes in Lebistes reticulatus. Genetics. 29: 584-592.

Hidebrand, S.F. 1921. Use of top minnows in malaria control. U. S. Public health Bull. 114: 34.

Houde, A.E. and J.A. Endler. 1995. Geographic variation in female preferences for male traits in Poecilia reticulata. Evolution. 49: 456-468.

Kaira, N.L., B.L. Wattal and N.G.S. Raghavan. 1967. Occurance of larvivorous fish Lebister reticulatus (Peters) breeding in sullage water at Nagpur-India. Bull. Ind. Soc. Mal. Com. Dis. 4: 253-254.

Khanum, S.I., H.R. Khan and A. Begum. 2002. Larvivorous potential of the guppy Poecilia reticulata on Culex quinquefasciatus larvae. Bangladesh. J. Zool. 30: 41-46.

Krumholz, L.A. 1948. Reproduction in the Western mosquito fish, Gambusia affinis, and its use in mosquito control. Ecol. Monorg. 18: 1-43.

Menon, P.K.B. and P.K. Rajagopalan. 1977. Mosquito control potential of some species of indigenous fishes in Pondicherry. Ind. J. Med. Res. 66: 765. 
Martyn, U., D. Weigel and C. Dreyer. 2006. In vitro culture of embryos of the guppy, Poecilia reticulata. Developmental Dynamics. 235: 617-622.

Peden, A.E. 1975. Differences in copulatory behaviour as partial isolating mechanisms in the Poecillid fish Gambusia. Can. J. Zool. 53: 1290-1296.

Shikano, T. and Y. Fujio. 1997. Successful propagation in seawater of the guppy Poecilia reticulata with reference to high salinity tolerance at birth. Fish. Science. 63: 573-575.

Tavolga, W.N. 1949. Embryonic development of the platyfish (Platypoecilus), the swordtail (Xiphophorus), and their hybrids. Bull Am Mus Nat Hist. 94:161-230.

Travis, B.V. 1957. Prent status and future possibilities of biologcal control of mosquitoes. Mosquito News. 17: 143-147.

WHO. 1986. Resistance of vectors and reservoirs of disease to pesticides. Tenth report of the WHO Expert Committee on Vector Biology and Control. Technical report Series. 737: 87.

(Received revised manuscript on 12 November 2013) 